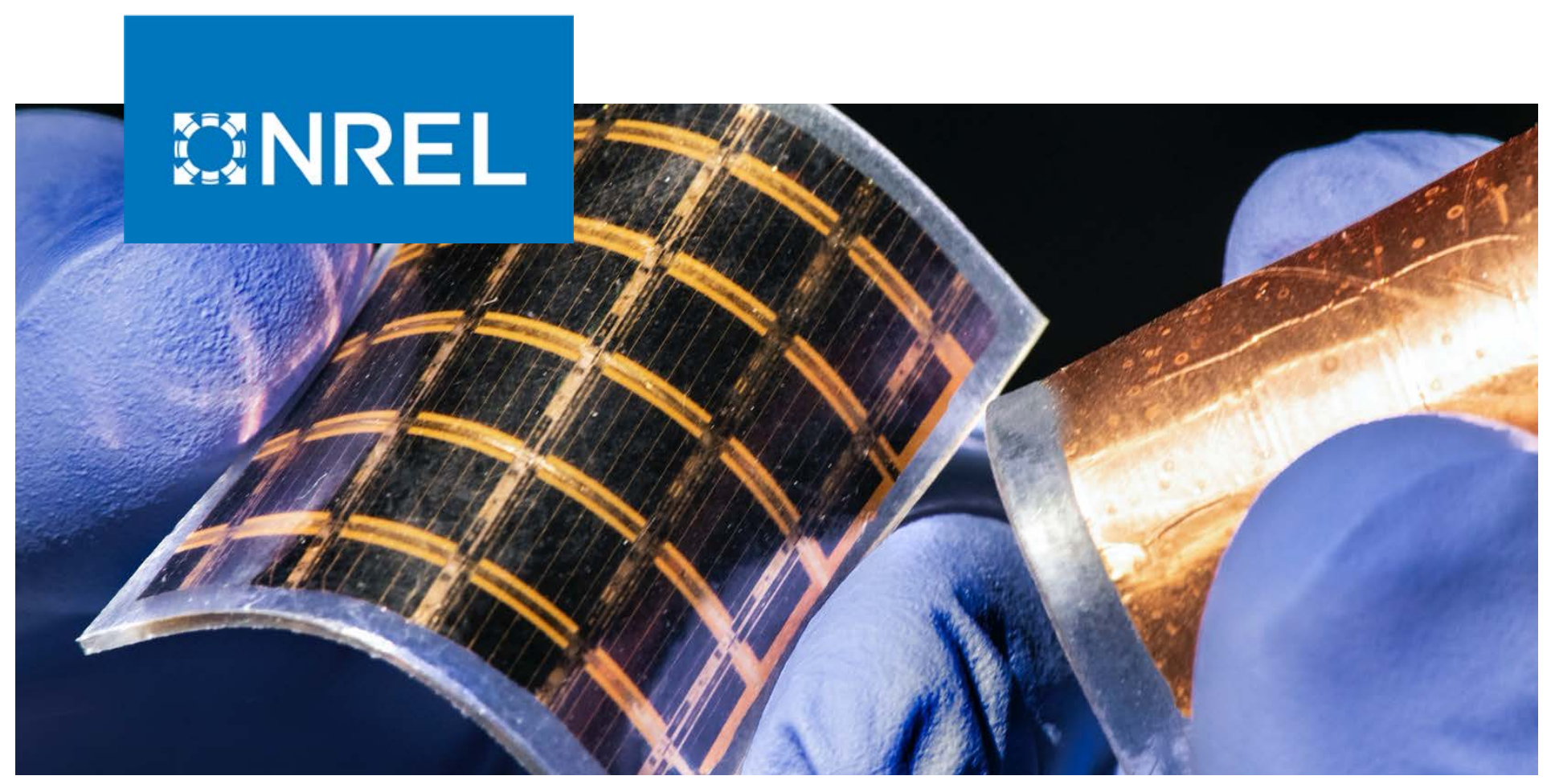

\title{
Radiation Effects in III-V Solar Cells Grown by Dynamic Hydride Vapor Phase Epitaxy
}

\author{
Aaron J. Ptak, Ryan M. France, and John Simon \\ National Renewable Energy Laboratory
}

NREL is a national laboratory of the U.S. Department of Energy Office of Energy Efficiency \& Renewable Energy

Operated by the Alliance for Sustainable Energy, LLC

This report is available at no cost from the National Renewable Energy Laboratory (NREL) at www.nrel.gov/publications.
Technical Report

NREL/TP-5900-79742

September 2021 


\title{
GNREL
}

\section{Radiation Effects in III-V Solar Cells Grown by Dynamic Hydride Vapor Phase Epitaxy}

\author{
Aaron J. Ptak, Ryan M. France, and John Simon
}

National Renewable Energy Laboratory

\section{Suggested Citation}

Ptak, Aaron J., Ryan M. France, and John Simon. 2021. Radiation Effects in III-V Solar Cells Grown by Dynamic Hydride Vapor Phase Epitaxy. Golden, CO: National Renewable Energy Laboratory. NREL/TP-5900-79742. https://www.nrel.gov/docs/fy21osti/79742.pdf.

NREL is a national laboratory of the U.S. Department of Energy Office of Energy Efficiency \& Renewable Energy Operated by the Alliance for Sustainable Energy, LLC

This report is available at no cost from the National Renewable Energy Laboratory (NREL) at www.nrel.gov/publications.

Contract No. DE-AC36-08GO28308
Technical Report

NREL/TP-5900-79742

September 2021

National Renewable Energy Laboratory 15013 Denver West Parkway Golden, CO 80401 303-275-3000 • www.nrel.gov 


\section{NOTICE}

This work was authored by the National Renewable Energy Laboratory, operated by Alliance for Sustainable Energy, LLC, for the U.S. Department of Energy (DOE) under Contract No. DE-AC36-08GO28308. Funding provided by OSD OE-Innovation / Operational Energy Capability Improvement Fund. The views expressed herein do not necessarily represent the views of the DOE or the U.S. Government.

This report is available at no cost from the National Renewable Energy Laboratory (NREL) at www.nrel.gov/publications.

U.S. Department of Energy (DOE) reports produced after 1991 and a growing number of pre-1991 documents are available free via www.OSTI.gov.

Cover Photo by Dennis Schroeder: NREL 55217.

NREL prints on paper that contains recycled content. 


\section{Executive Summary}

The recent development of hydride vapor phase epitaxy (HVPE) is potentially promising as a route to lower the cost of high-efficiency III-V solar cells for space applications. HVPE produces the same materials and device structures as the industry-standard organometallic vapor phase epitaxy (OMVPE) process, and although HVPE has shown promising device efficiencies, it lags the OMVPE growth technique in technical maturity. For example, there are no reports of the performance of HVPE-grown devices in radiation environments. There is an expectation that high-quality (that is, single crystal and low-defect) III-V materials will behave similarly regardless of the growth method. However, it is important to verify assumptions as facts.

In this project, we produced materials and devices using both HVPE and OMVPE at NREL and irradiated them using $1 \mathrm{MeV}$ electrons to ascertain the effect of radiation on the materials. We also performed initial work on producing more radiation-hard structures, including devices with the $p-n$ junction at the front of the device, and devices with a graded doping profile, both of which help with radiation tolerance.

Measurements of the devices post radiation exposure showed that the open-circuit voltage ( $\left.V_{O C}\right)$ of the HVPE-grown solar cells degraded least on a percent basis, although they also started from a lower baseline than the OMVPE-grown devices. All solar cells reached approximately the same $V_{O C}$ after irradiation, indicating that the dose used was sufficient to degrade all devices equally. The short-circuit current in the HVPE devices did degrade more than the other solar cells, and this was attributed to a higher-than-expected doping density in the base layer of that cell.

The results of these experiments, while by no means comprehensive, do not show any material difference in the radiation effects in OMVPE- and HVPE-grown materials and devices.

\section{Acknowledgements}

We would like to thank the OSD OE-Innovation/Operational Energy Capability Improvement Fund for supporting this work. We are also very grateful to Yao Lao and Don Walker from The Aerospace Corporation for allowing us to piggyback on their radiation testing. We also thank Fred Bateman at NIST for performing the radiation exposures. In addition, we thank Waldo Olavarria, David Guiling, Michelle Young, and Evan Wong for materials growth and processing. We are also indebted to Dave Wilt at AFRL for substantial guidance and advice during this work. This work was authored by Alliance for Sustainable Energy, LLC, the manager and operator of the National Renewable Energy Laboratory for the U.S. Department of Energy (DOE) under Contract No. DE-AC36-08GO28308. This material is based upon work supported by the OSD OE-Innovation/Operational Energy Capability Improvement Fund. The views expressed in the article do not necessarily represent the views of the DOE or the U.S. Government. The U.S. Government retains and the publisher, by accepting the article for publication, acknowledges that the U.S. Government retains a nonexclusive, paid-up, irrevocable, worldwide license to publish or reproduce the published form of this work, or allow others to do so, for U.S. Government purposes. 


\section{Table of Contents}

Executive Summary ........................................................................................................................... iii

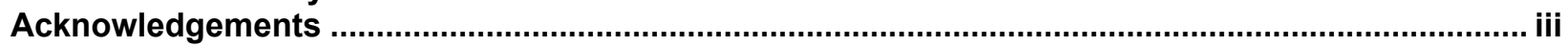

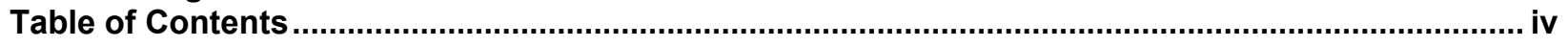

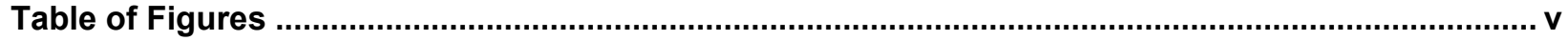

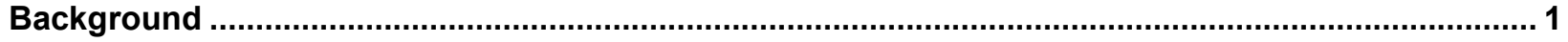

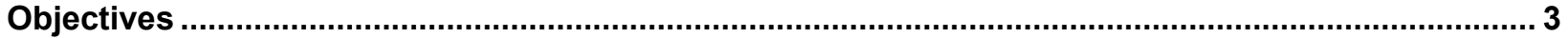

Development of front-junction device structures using D-HVPE ...................................................... 3

Development of graded base doping using both D-HVPE and OMVPE .......................................... 5

Assessment of solar cell performance after irradiation and post-irradiation recovery .......................... 5

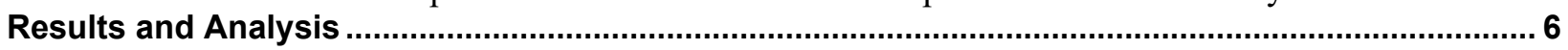

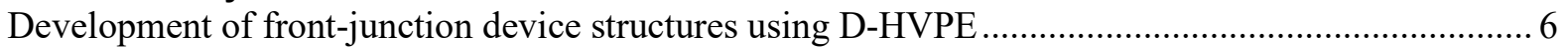

Development of graded base doping using both D-HVPE and OMVPE .......................................... 6

Assessment of solar cell performance after irradiation and post-irradiation recovery .......................... 8

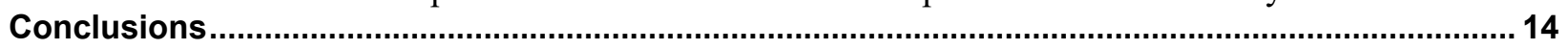

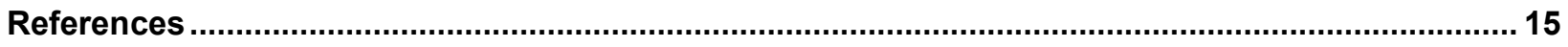

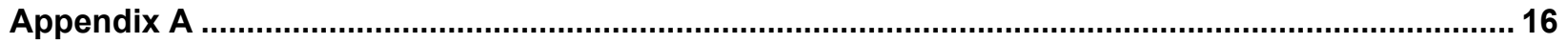




\section{Table of Figures}

Figure 1. Schematic representation of the D-HVPE reactor under construction. ....................................... 1

Figure 2. Schematic representation of the current, custom D-HVPE reactor in use at NREL..................... 3

Figure 3. Front and rear junction solar cell structures. .................................................................. 4

Figure 4. Comparison of the performance of irradiated solar cells as a function of junction depth showing that front junction structures maintain higher performance compared to rear junctions. From [9].

Figure 5. Schematic showing the carrier doping profile that creates an electric field within the device that helps carrier collection when diffusion lengths decrease due to radiation damage. ................ 5

Figure 6. Current-density-voltage (JV) measurement of a front-junction GaAs solar cell grown using DHVPE under AM0 (space) illumination conditions. The efficiency was $~ 20 \%$. ................... 6

Figure 7. Secondary-ion mass spectrometry (SIMS) measurement showing the $\mathrm{Zn}$ and Se concentrations as a function of depth in a solar cell grown using D-HVPE. The Zn profile shows graded doping.

Figure 8. JV curves comparing the performance of two D-HVPE-grown GaAs solar cells, with graded or constant $\mathrm{Zn}$ doping in the base layer.

Figure 9. Comparison of $\mathrm{Zn}$ doping determined by capacitance-voltage (CV) and SIMS measurements, along with the intended profile.

Figure 10. Comparison of OMVPE-grown GaAs solar cell JV curves for devices with flat or exponential doping. The devices each have conversion efficiencies of $\sim 21.5 \%$ under AM0 conditions... 8

Figure 11. TRPL lifetime measurements comparing HVPE- and OMVPE-grown GaAs DH structures..... 9

Figure 12. Pre- and post-irradiation JV curves for the solar cell structures tested here. The right column shows the same data as on the left, magnified near the open-circuit voltage.......................... 11

Figure 13. Solar cell parameters measured from the JV curves shown in Figure 12 ............................... 12

Figure 14. Solar cell parameters shown in Figure 13, normalized to unity. ............................................ 12

Figure 15. Modeling of the IQE for the HVPE-grown solar cell for both before (left) and after (right)

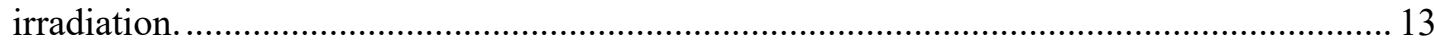

Figure 16. Minority-carrier lifetimes calculated from time-resolved photoluminescence measurements of irradiated DH structures as a function of laser illumination time. 


\section{Background}

The production of $24 \%$ efficient (AM0) single-junction GaAs-based (III-V) solar cells and 28\% efficient two-junction devices at costs below $\$ 30 / \mathrm{W}$ is a critical enabler for next-generation space power applications. Current solar technologies like silicon or cadmium telluride are not well-suited for space, and emerging technologies require significant research to understand their potential value in these demanding environments. Solar cells based on GaAs, however, have the highest light-to-electricity conversion efficiency, with single-junction devices achieving $29.1 \%$ under 1-sun (terrestrial) illumination [1]. Additionally, these devices have the highest power-tomass ratio $(\mathrm{W} / \mathrm{kg})$ and lowest temperature coefficient [2] of any cell technology, making them ideal for light-weight, high-power applications that maintain their efficiency advantage in extreme, high- and low-temperature conditions. Importantly, III-V cells have a proven track record of reliability in very demanding space applications. Currently, however, these thin, stable, light, and flexible solar cells cost between $\$ 150$ - \$200/W, making them prohibitively expensive for use in large-area, high-power solar arrays. Solar cell costs today can be in excess of $50 \%$ of the entire cost of a large orbital installation. Drastically decreasing the cost of high-efficiency III$\mathrm{V}$ solar cells can enable projects that are currently not feasible.

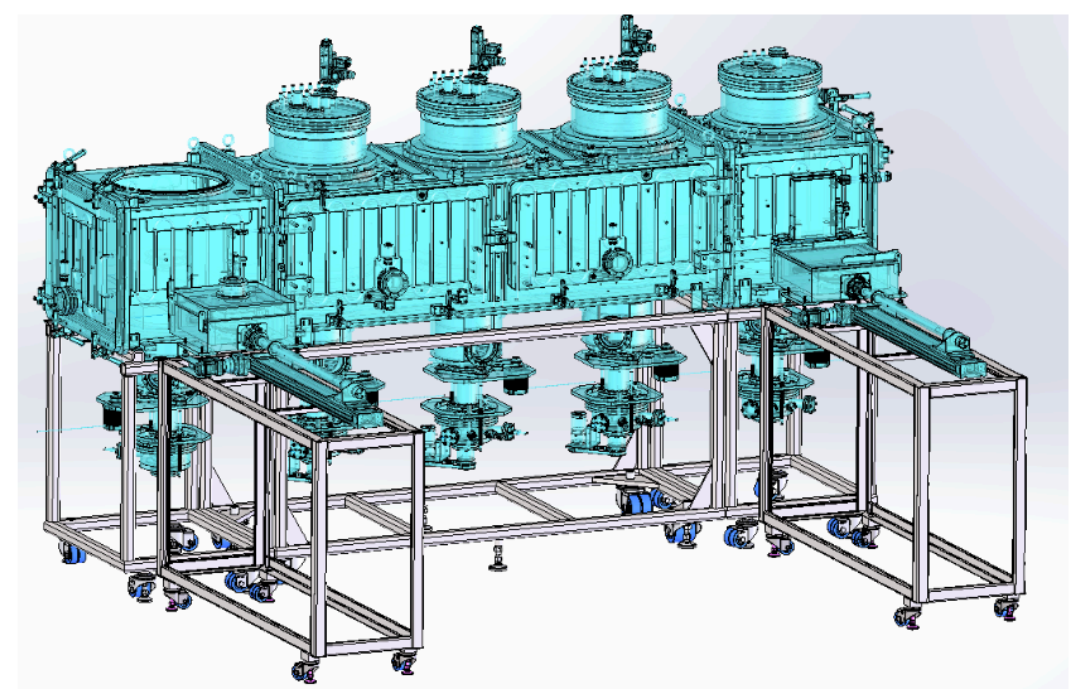

Figure 1. Schematic representation of the D-HVPE reactor under construction.

There are three major costs associated with the production of GaAs-based solar cells, each of which needs to be reduced before widespread adoption in large-area space applications can occur: the costs associated with epitaxial growth, substrate reuse, and back-end processing. Scaling the overall manufacturing process also plays a critical role in achievable costs.

New manufacturing platform for low-cost epitaxial growth: Hydride vapor-phase epitaxy (HVPE) is a well-established route to grow very high-quality semiconductors. Compared with organometallic vapor phase epitaxy (OMVPE) growth, HVPE has $>10 \mathrm{x}$ higher deposition rate, uses input materials that are 10x less expensive, has a much higher material utilization rate, and lends itself to a low-cost, in-line deposition process [3]. All together these features make HVPE a low-cost manufacturing technique. HVPE is currently used in the batch manufacturing of substrates for LEDs and power electronics devices, but has not been used to produce devices themselves due to difficulties in growing clean and abrupt interfaces-until now. 
NREL developed a pseudo in-line prototype Dynamic-HVPE (D-HVPE) growth reactor for GaAsbased devices that solves the interface growth problem by rapidly moving the substrate between different growth chambers separated by gas curtains. D-HVPE research showed, for the first time, $\mathbf{> 2 5 \%}$ efficient AM1.5G GaAs solar cells grown 30x faster than OMVPE [4]. NREL also demonstrated the world's first HVPE-grown two-junction devices with a direct path to $>28 \%$ AM0 efficiency. Currently, NREL is engaged in designing and building a three-chamber, pseudo in-line D-HVPE reactor with the capability to deposit on industry-standard 6" wafers, shown in Figure 1. This new system, once delivered, will dramatically increase the throughput of III-V solar devices through significantly higher growth rates and the use of the pseudo in-line process.

Lower costs are not always valuable, however, if the materials and devices do not perform equivalently to existing products. The space environment subjects solar cells to high levels of electron and proton radiation, depending on the orbit, that create point defects within the materials. These defects adversely affect the performance of the devices, leading to decreasing conversion efficiencies throughout the mission. Fortunately, the degradation mechanisms are well-understood and fairly predictable as a function of radiation fluence and energy. Irradiation using controlled conditions in a terrestrial setting is often used to determine degradation rates for different materials and device structures. It is important to quantify the degradation of solar cells grown by the new D-HVPE method to understand if they will perform equally well as current devices in the relevant space environments. It is likely that all III-V materials, regardless of growth method, will perform similarly, i.e., "GaAs is GaAs." However, it is also possible that a specific growth method may lead to a difference in the original point defect types or concentrations that lead to different overall behavior upon irradiation. 


\section{Objectives}

There are three main objectives in this work:

1. Development of front-junction device structures using D-HVPE

2. Development of graded base doping using both D-HVPE and OMVPE

3. Assessment of solar cell performance after irradiation and post-irradiation recovery

\section{Development of front-junction device structures using D-HVPE}

Growth of device structures using our current, custom, two-chamber D-HVPE system at NREL, shown in Figure 2, involves depositing a layer on a substrate in one growth chamber while establishing growth conditions for a subsequent layer in the adjacent chamber. The substrate then moves to the adjacent chamber for growth of that specific device layer in a process known as dynamic HVPE, and the procedure continues until the entire device structure is complete. This substrate motion is in contrast to the standard OMVPE growth method that switches gases and relies on plug flow to create abrupt interfaces between layers and is necessary in HVPE growth due to high growth rates and significant chemical inertia during the growth process, which is described in more detail elsewhere $[5,6]$. For the purposes of this study, the D-HVPE process used here results in layers of a specific material, alloy composition, doping, or growth rate being calibrated in a specific growth chamber, and each layer being somewhat dependent on the order in which layers are deposited, again in contrast to OMVPE growth. Any device structure can be obtained using D-HVPE, but the practical ramifications of this approach are that a change in structure requires recalibration of the entire layer stack.

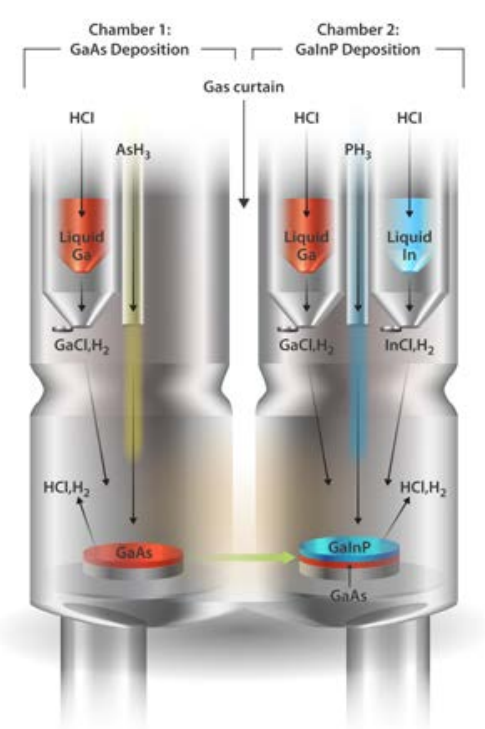

Figure 2. Schematic representation of the current, custom D-HVPE reactor in use at NREL. 
Before this project, most GaAs solar cells grown by D-HVPE used a rear heterojunction (RHJ) structure that is more appropriate for terrestrial applications. The RHJ structure, shown schematically in Figure 3 (left), results in a slightly higher efficiency due to lowered depletion region recombination at the buried heterointerface $[7,8]$. However, this structure depends on the diffusion of minority-carrier holes and requires very high material quality. The literature shows that structures with deep junctions do not fare well in space environments once radiation-induced degradation begins, as shown in Figure 4 [9]. Therefore, we developed the front junction structure, also shown in Figure 3 (right), by D-HVPE as a part of this project to improve radiation resistance.

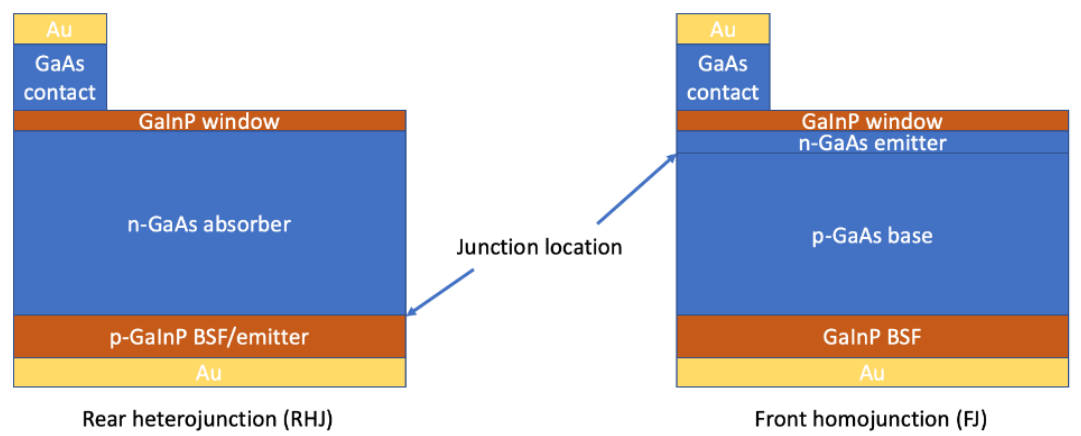

Figure 3. Front and rear junction solar cell structures.

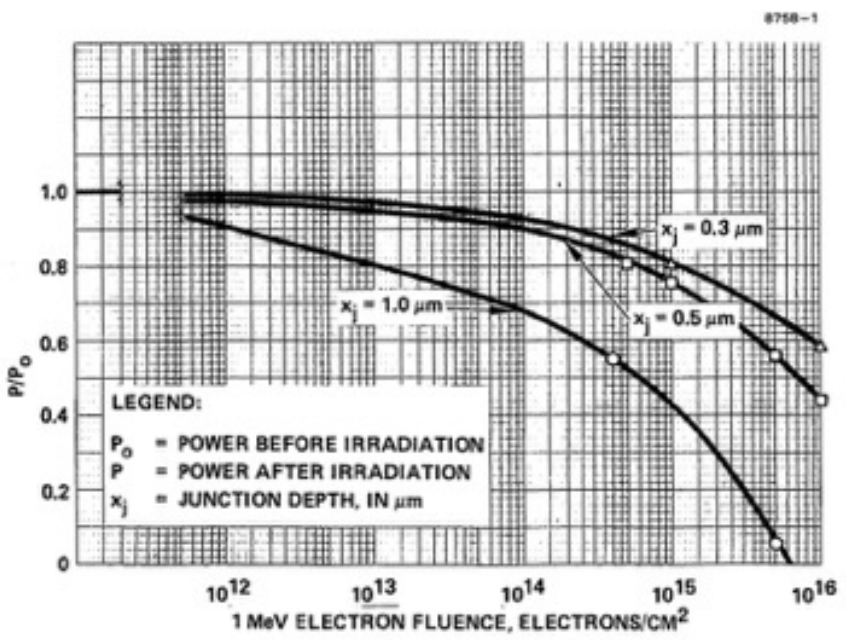

Figure 4. Comparison of the performance of irradiated solar cells as a function of junction depth showing that front junction structures maintain higher performance compared to rear junctions. From [9]. 


\section{Development of graded base doping using both D-HVPE and OMVPE}

Another structural change that improves radiation resistance is the incorporation of graded doping in the solar cell absorber layer, shown schematically in Figure 5. This grade creates an electric field within the device that helps to "sweep" minority carriers toward the junction. Typically, carriers diffuse to the junction, but this process relies on high material quality and long minority-carrier diffusion lengths, which are controlled in large part by point defects. Radiation increases the point defect concentration in the solar cell and decreases the diffusion length. Once the average diffusion length is less than the distance the carriers need to travel for collection, performance suffers. The electric drift field works as a boost to the diffusion process and continues to allow for carrier collection when the diffusion length decreases.

Graded layers are what D-HVPE was specifically designed to avoid, and despite decades of research on OMVPE growth of solar cells at NREL, there was little experience creating these doping profiles. Therefore, this project aimed to develop graded doping in front-junction solar cells by both OMVPE and D-HVPE.

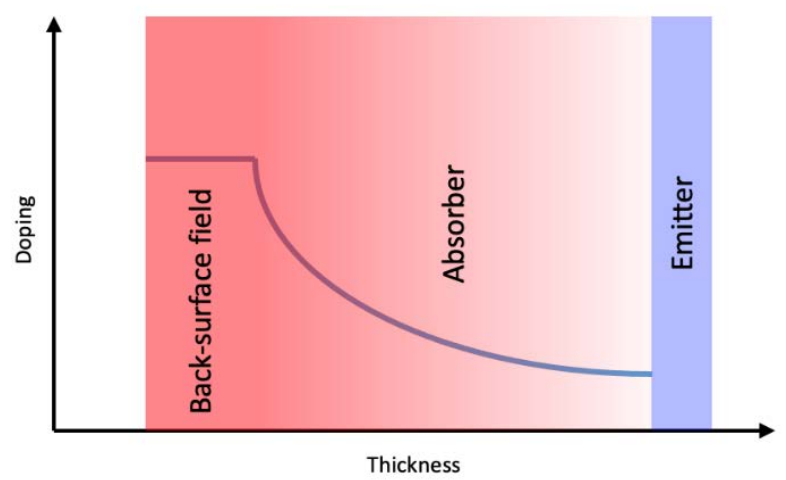

Figure 5. Schematic showing the carrier doping profile that creates an electric field within the device that helps carrier collection when diffusion lengths decrease due to radiation damage.

\section{Assessment of solar cell performance after irradiation and post- irradiation recovery}

This was the main objective of this project. There was an expectation that GaAs solar cells with similar terrestrial performance would perform similarly under space conditions regardless of how they were created. However, it is important to positively establish that this is the case. We deposited GaAs solar cells by both OMVPE and D-HVPE with as close to the same structure as possible and irradiated them with high-energy electrons to show how each degraded. We also performed post-irradiation annealing and light soaking to show how each responded. The results from these experiments are detailed below. 


\section{Results and Analysis}

\section{Development of front-junction device structures using D-HVPE}

As discussed above, growth of a front-junction structure by D-HVPE, like the one shown in Figure 3, required re-optimization of each of the device layers. This took time but did not present any serious technical challenges. Figure 6 shows the current-density-voltage $(\mathrm{JV})$ measurement of a frontjunction GaAs solar cell grown by D-HVPE. The measurement used AM0 illumination conditions and resulted in an open-circuit voltage $\left(V_{O C}\right)$ of $\sim 1.03 \mathrm{~V}$ and a conversion efficiency of $\sim 20 \%$.

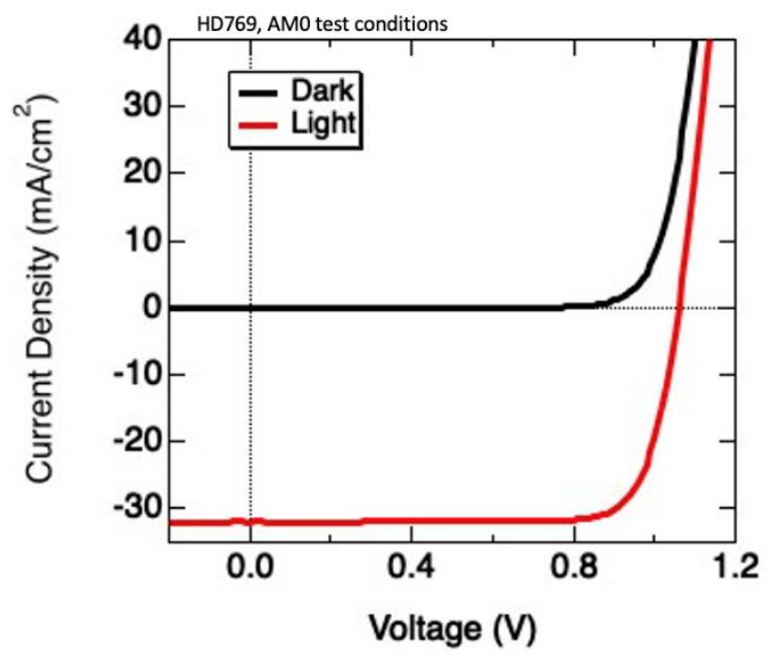

Figure 6. Current-density-voltage (JV) measurement of a front-junction GaAs solar cell grown using D-HVPE under AMO (space) illumination conditions. The efficiency was $\sim 20 \%$.

\section{Development of graded base doping using both D-HVPE and OMVPE}

Doping with $\mathrm{Zn}$ in the D-HVPE systems is complicated by the fact that there is $\sim 10 \mathrm{~m}$ of $1 / 4$ " stainless steel line between the $\mathrm{Zn}$ source (a diethylzinc bubbler) and the growth reactor. It takes a significant amount of time (several minutes, at least, depending on the total flow in the line) to prime these lines with $\mathrm{Zn}$, and an equal amount of time for any changes in the $\mathrm{Zn}$ flow to reach the growth surface. This makes the deposition of a layer with a controlled graded doping profile difficult to achieve in practice. The growth rates in HVPE are typically very high, minimally on the order of $1 \mu \mathrm{m} / \mathrm{min}$. Thus, a $2-\mu \mathrm{m}$-thick base layer is finished before meaningful changes to the $\mathrm{Zn}$ flow can be made.

We were able to achieve some level of $\mathrm{Zn}$ profile control by changing the $\mathrm{Zn}$ flow well before it was needed for the base layer growth. Figure 7 shows a secondary ion mass spectrometry (SIMS) measurement of the $\mathrm{Zn}$ concentration in a D-HVPE-grown GaAs solar cell, with the $\mathrm{Zn}$ concentration rising toward the back of the device and creating an electric field that aids carrier drift. This profile is not optimal, but it did achieve a conversion efficiency on par with a similar solar cell grown with constant doping. Figure 8 shows a comparison of the $J V$ curves for these devices, measured under the AM1.5G terrestrial spectrum. They are expected to be $\sim 20 \%$ efficient under AM0 space conditions. 


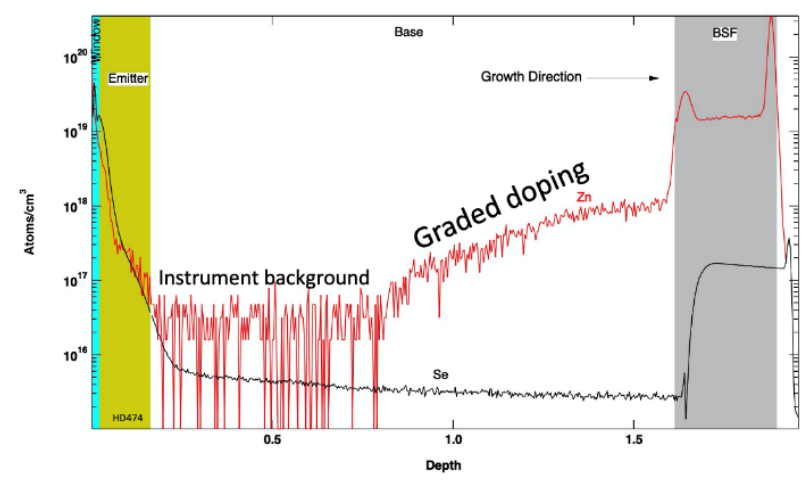

Figure 7. Secondary-ion mass spectrometry (SIMS) measurement showing the Zn and Se concentrations as a function of depth in a solar cell grown using D-HVPE. The $\mathrm{Zn}$ profile shows graded doping.

Graded doping development was more straightforward by OMVPE. We performed calibrations to determine the $\mathrm{Zn}$ concentration resultant in GaAs as a function of $\mathrm{Zn}$ mass flow controller settings, then used these data to design an exponential doping profile. Figure 9 shows measurements of the acceptor doping from capacitance-voltage measurements, the Zn concentration from SIMS measurements, and the designed doping profile. There is reasonable agreement between the data. Figure 10 shows a comparison of solar cells grown by OMVPE with either a flat doping profile or the profile shown in Figure 9. The performance of the two devices is nearly identical, with AM0 space performance of $\sim 21.5 \%$ conversion efficiency.

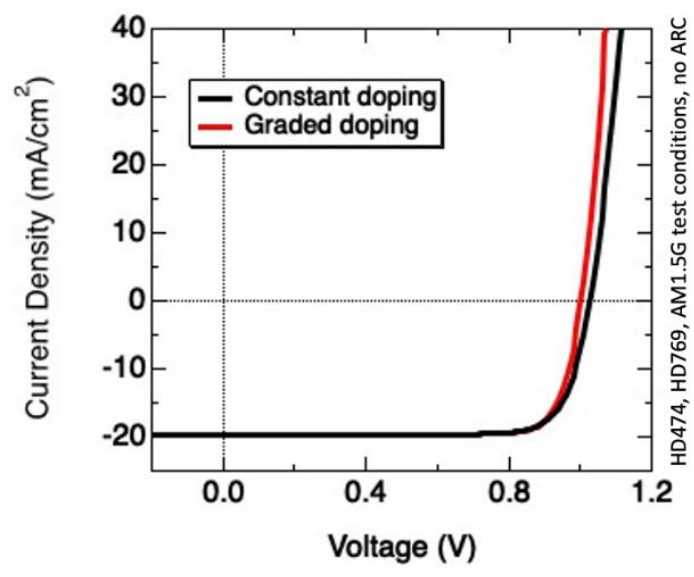

Figure 8. JV curves comparing the performance of two D-HVPE-grown GaAs solar cells, with graded or constant $\mathrm{Zn}$ doping in the base layer.

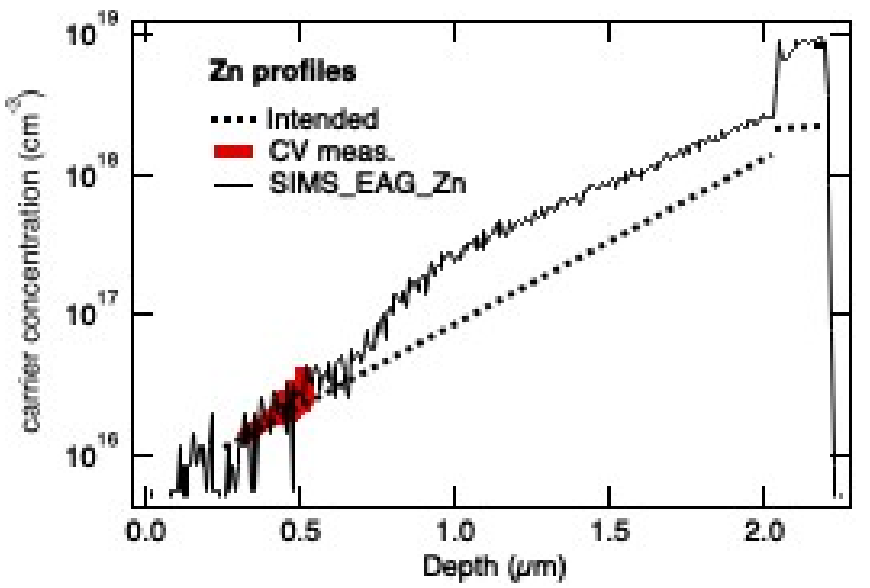

Figure 9. Comparison of $\mathrm{Zn}$ doping determined by capacitance-voltage (CV) and SIMS measurements, along with the intended profile. 


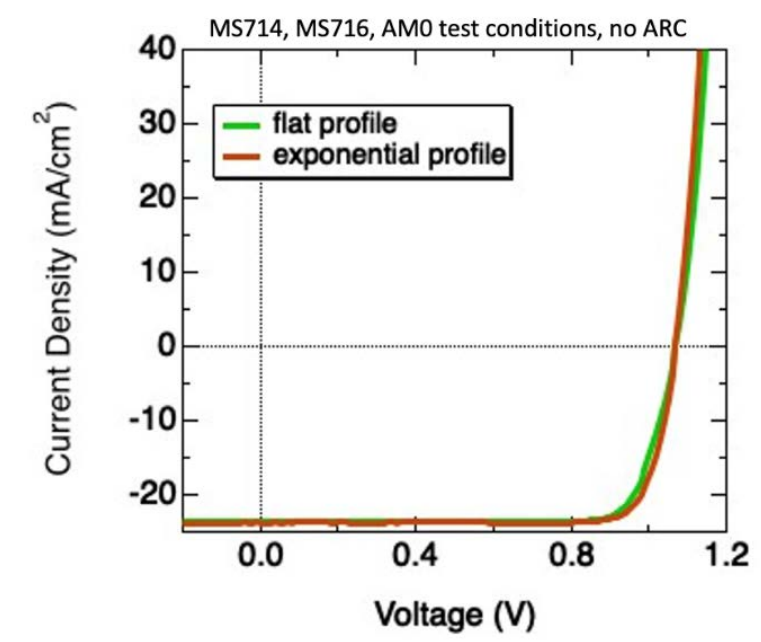

Figure 10. Comparison of OMVPE-grown GaAs solar cell JV curves for devices with flat or exponential doping. The devices each have conversion efficiencies of $\sim 21.5 \%$ under AM0 conditions.

\section{Assessment of solar cell performance after irradiation and post- irradiation recovery}

We produced two different structures for testing with high-energy radiation. The first was a front junction (FJ) solar cell structure like those shown in the right side of Figure 3 . The FJ structures allow for measurement of the full $J V$ curve before and after irradiation, as well as the doping of the base through capacitance techniques. As shown above, graded doping by HVPE was problematic so only flat doping samples were produced by HVPE for this study. We were able to measure both flat and exponentially-doped devices grown by OMVPE. The doping of the HVPEgrown device was higher than intended, $\sim 5 \times 10^{17} \mathrm{~cm}^{-3}$ instead of $1 \times 10^{17} \mathrm{~cm}^{-3}$. This likely decreased the minority-carrier lifetime and diffusion length in these devices, in part contributing to the lower performance compared to the OMVPE-grown cells. However, we do not expect that this difference materially alters the conclusions of this study. We grew these cells with relatively thick base layers, measured in each cell to be $\sim 1.9 \mu \mathrm{m}$, to better observe degradation in the short-circuit current density $\left(J_{S C}\right)$.

The second structures that we produced were double heterostructures (DHs), which are "sandwiches" of a material of interest, in this case GaAs, clad on the front and back surfaces with a higher bandgap material, here GaInP. The DH structures allow for the measurement of the minority-carrier lifetime by using time-resolved photoluminescence (TRPL). This measurement involves illuminating a sample with a very fast laser pulse and recording the intensity of the resultant luminescence as a function of time. This leads to an estimate of the minority-carrier lifetime, that is, the longer the photoluminescence persists, the longer the carrier lifetime, although this analysis can be complicated by carrier trapping. Our measurements used a $670 \mathrm{~nm}$ laser with a 
$1 \mathrm{MHz}$ duty cycle. Typically, TRPL measurements use samples of varying thickness to extract the interface recombination velocity and the bulk minority-carrier lifetime, according to:

$$
\frac{1}{\tau_{T R P L}}=\frac{1}{\tau_{b u l k}}+\frac{2 S}{d}
$$

where $\tau_{b u l k}$ is the minority carrier lifetime of the material of interest, $S$ is the interface recombination velocity, and $d$ is the thickness of the layer. All structures were irradiated at the National institute of Standards and Technology using $1 \mathrm{MeV}$ electrons and different total fluences, as described below, and as shown in Table II in Appendix A. The structures were measured before and after irradiation, then were subjected to additional post-irradiation recovery efforts. The first was a $24 \mathrm{~h}$ anneal at $60^{\circ} \mathrm{C}$ in the dark, and the second was a $48 \mathrm{~h}$ light soak using AM0 illumination at $28^{\circ} \mathrm{C}$. Structures were also measured after each of these steps.

Figure 11 shows the TRPL lifetimes measured from HVPE- and OMVPE-grown GaAs DHs with different GaAs thicknesses. There is a difference in the lifetimes between the two sets prior to irradiation, with OMVPE samples having typical lifetimes near $9 \mathrm{nsec}$, compared to $\sim 3 \mathrm{nsec}$ for HVPE samples. Again, this is likely due to the higher base doping in the HVPE-grown structures. For reference, the radiative lifetimes for GaAs doped at either 1 or $5 \times 10^{17} \mathrm{~cm}^{-3}$ are $50 \mathrm{nsec}$ and $10 \mathrm{nsec}$, respectively. We attempted to extract values for $S$ and $\tau_{b u l k}$ but there was enough scatter in the data to make the fits unreliable. From the flatness of the trends, we can infer that the recombination velocity is below $1000 \mathrm{~cm} / \mathrm{s}$ and unlikely to be a limiting factor in solar cells grown using these conditions. Upon irradiation with a fluence of $1 \times 10^{15} \mathrm{~cm}^{-2} 1 \mathrm{MeV}$ electrons, all samples, regardless of growth method, had lifetimes of $0.2-0.3 \mathrm{nsec}$. We irradiated other DH structures with other fluences of electrons but did not have the resources necessary to complete the measurements and analysis.

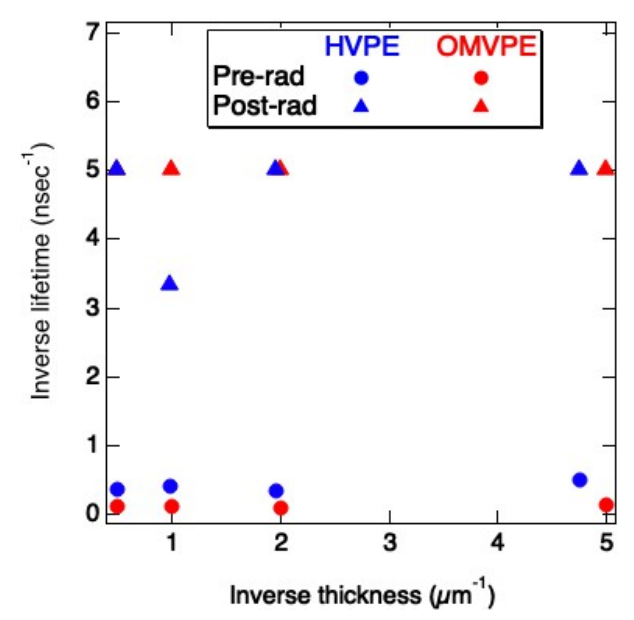

Figure 11. TRPL lifetime measurements comparing HVPE- and OMVPE-grown GaAs DH structures. 
We also irradiated the FJ solar cells with $1 \times 10^{15} \mathrm{~cm}^{-2} 1 \mathrm{MeV}$ electrons. Figure 12 shows results of the pre- and post-irradiation measurements. The plots in the left column show the preirradiation $J V$ curves in black. Note that none of these devices had an anti-reflection coating applied. The red data in each case is the $J V$ measurement taken directly after $1 \mathrm{MeV}$ electron irradiation. The green and blue data are the measurements after the dark anneal and light soak conditions described above, respectively. The plots in the right column are the same data, but magnified in the region around $V_{O C}$. Clearly, the $1 \mathrm{MeV}$ electron irradiation caused significant degradation in each case in both the $V_{O C}$ and the $J_{S C}$. Figure 13 shows the $V_{O C}, J_{S C}$, fill factor (FF) and efficiency determined from the data in Figure 12 for each of the measurement conditions. Figure 14 shows the same data, normalized to unity.

It is clear from the normalized data shown in Figure 14 that the HVPE-grown solar cell had the lowest percent change in $V_{O C}$ of any of the devices measured. However, this device also started with the lowest $V_{O C}$ and can hence be considered "pre-degraded" in some sense. As discussed above, this beginning of life (BOL) degradation is most likely due to the high base doping, and hence lower lifetime, in these devices compared to the OMVPE growths. After irradiation with a fluence of $1 \times 10^{15} \mathrm{~cm}^{-2} 1 \mathrm{MeV}$ electrons, all the devices showed essentially identical $V_{O C}$. This likely means that if the HVPE-grown device had started with a higher $V_{O C}$, that it too would have had a relatively larger percent change and ended up at the same level as the OMVPE-grown solar cells. This seems to indicate that even though the devices started with different performance levels, this fluence of $1 \mathrm{MeV}$ electrons was sufficient to degrade them all to the same final state.

The degradation in the $J_{S C}$ for the HVPE-grown cells, however, is quite a bit larger than for the OMVPE-grown devices. This is the primary reason that the irradiated efficiency of the HVPE solar cells is the lowest of the set, rather than serious degradation of the $V_{O C}$. It is possible that the higher-than-expected doping in the HVPE-grown device is responsible for this effect. The high doping will lead to a shorter minority-carrier diffusion length in the as-grown material. Upon irradiation, it is possible that this diffusion length becomes short enough to significantly affect the carrier collection, especially in the absence of an electric field arising from a built-in graded doping profile. We note that the $J_{S C}$ of the OMVPE-grown solar cell with the exponential doping fared quite well, and that while there was degradation in the flat-doped version, it may not have been as severe as the HVPE cell due to the lower original base doping. To test this, we modelled the internal quantum efficiency (IQE) for each of the solar cells using data generated before and after irradiation. Figure 15 shows the modeled fits for the HVPE-grown device. We performed similar modeling for the OMVPE devices. It is difficult to get an accurate fit when the minority-carrier diffusion length is significantly longer than the thickness of the base layer. In this case we can only estimate that it is larger than some minimum value. In the case of this modeling effort, we estimate that both the OMVPE and HVPE solar cells had diffusion lengths $>5 \mu \mathrm{m}$ before irradiation. After irradiation, both devices showed similar degradation, as shown in Table I. Because of the square root dependence of the diffusion length on the minority-carrier lifetime, these data also agree with the TRPL data. There was an order of magnitude decrease (or more) in the decay lifetime upon irradiation, which would lead to a decrease in the diffusion length of three to four times, which is approximately what we see here. 

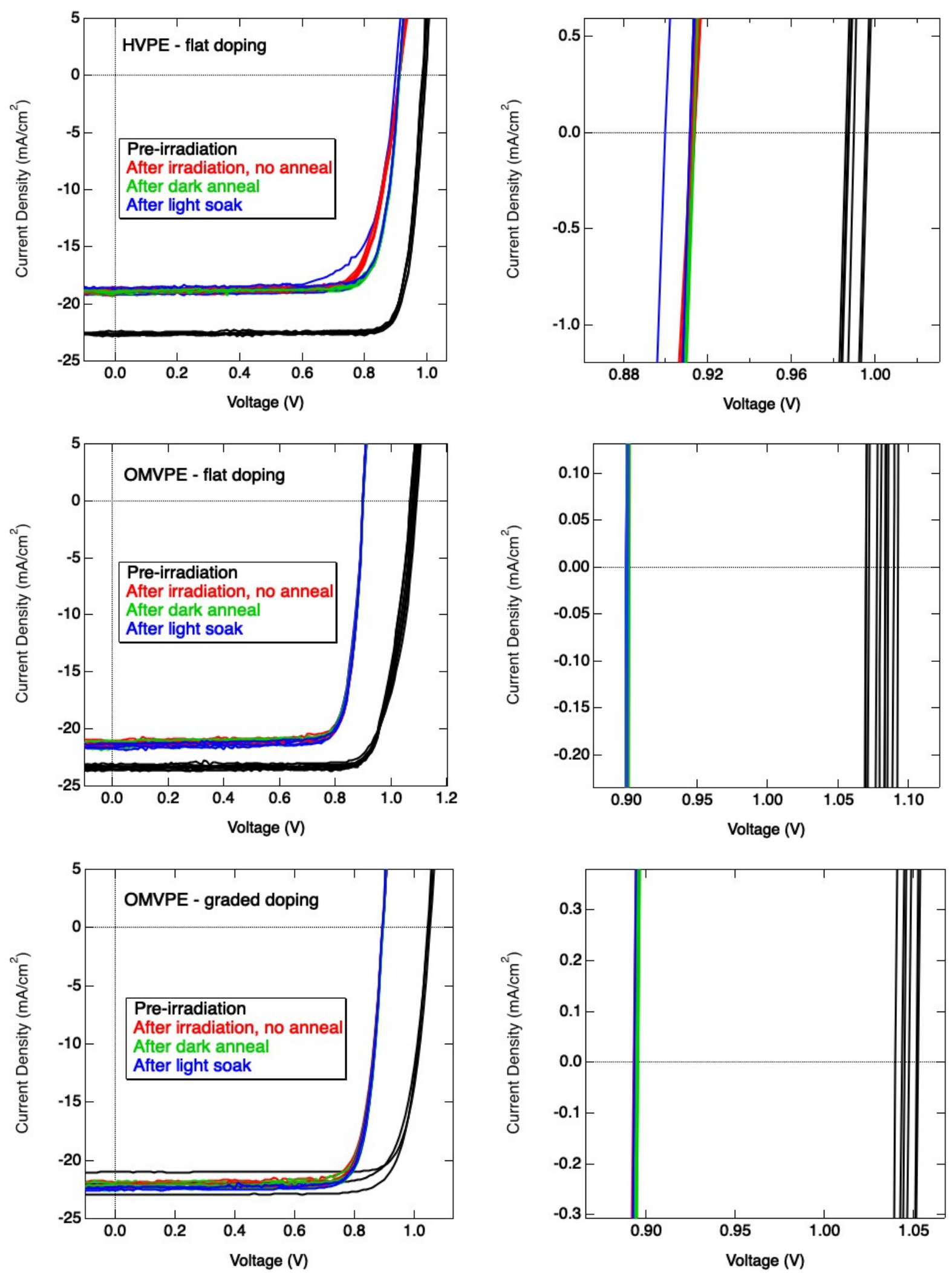

Figure 12. Pre- and post-irradiation JV curves for the solar cell structures tested here. The right column shows the same data as on the left, magnified near the open-circuit voltage. 


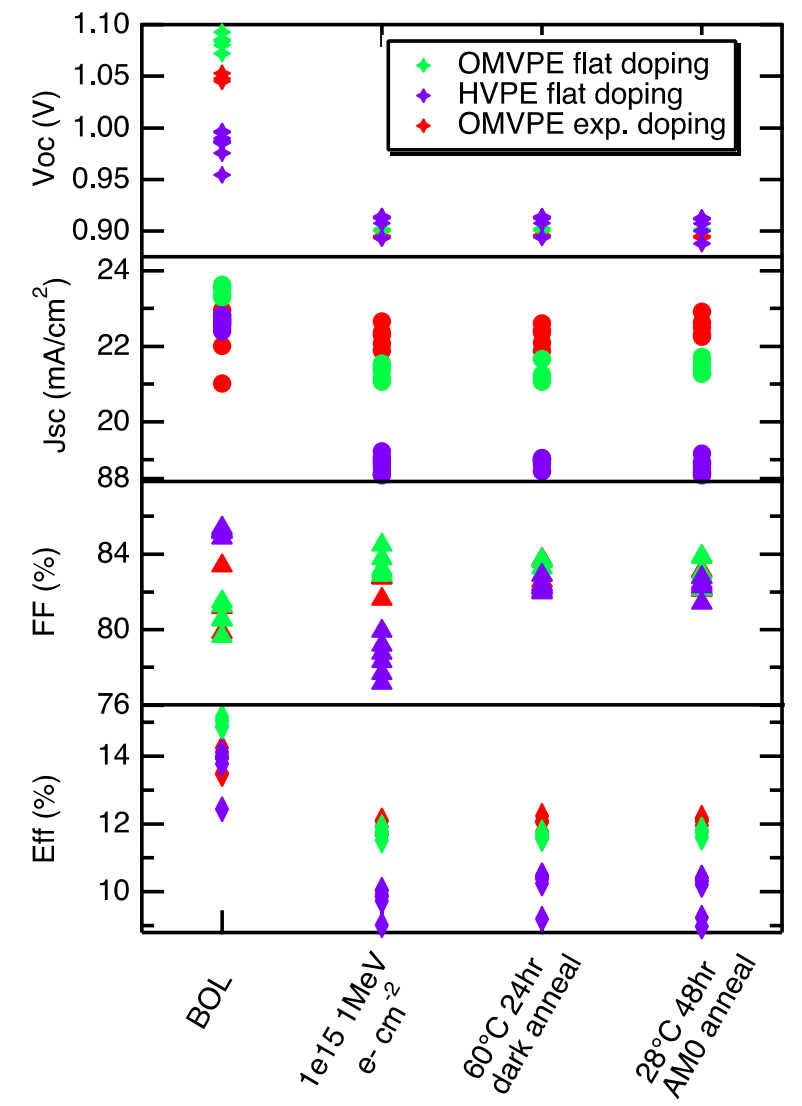

Figure 13. Solar cell parameters measured from the JV curves shown in Figure 12.

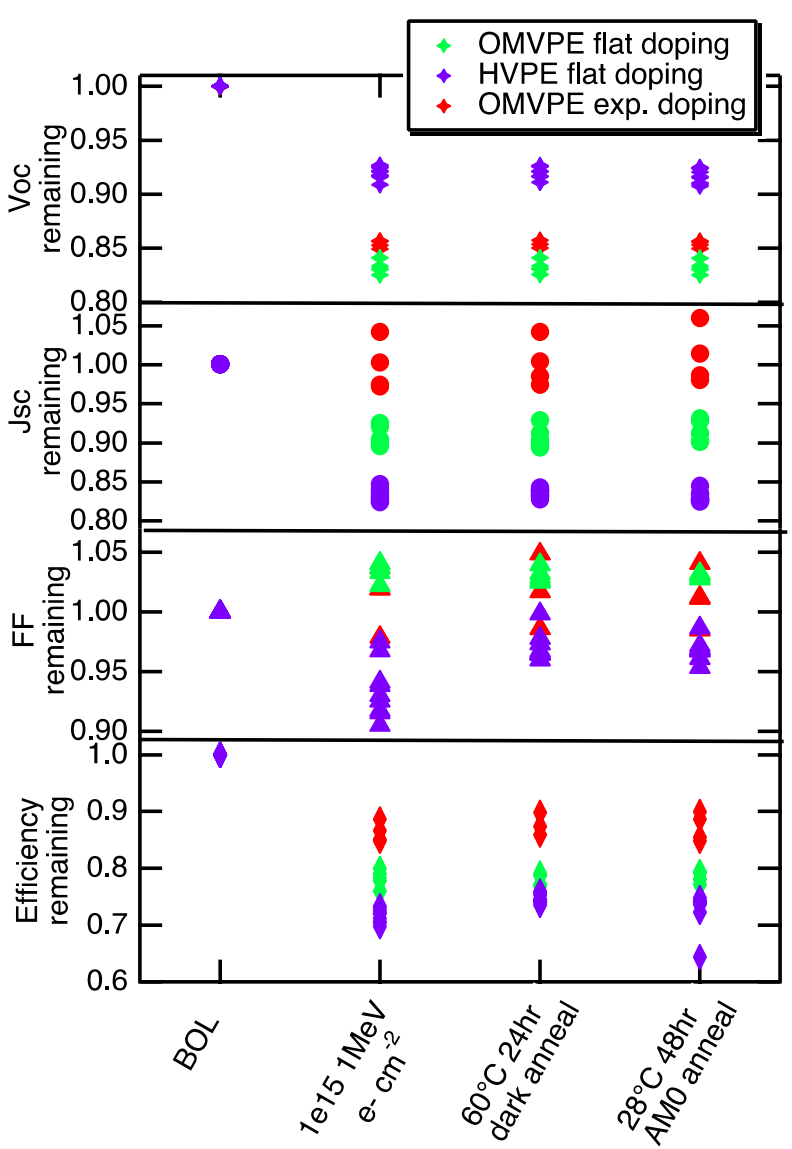

Figure 14. Solar cell parameters shown in Figure 13, normalized to unity.

We believe that the OMVPE-grown device had a higher diffusion length than the HVPE sample before irradiation because of its lower base doping. Measurements showed that none of the base doping levels changed throughout these experiments. Other structural changes, in addition to attaining a proper doping profile, can help with $J_{S C}$ retention as well, including thinner base layers and the use of a metallic back reflector or distributed Bragg reflector.

We performed the dark annealing and light soaking experiments that form part of the qualification standards set forth by the U.S. and European communities. Clearly, the experiments performed here are nowhere near as rigorous as required for full qualification but are intended to provide initial information of the degradation of HVPE-grown materials and devices. The additional processing resulted in minor improvements in the $J_{S C}$ for some devices, and the FF of the HVPE solar cells, but little else of note.

Table I. Estimated diffusion lengths from the IQE fitting shown in Figure 15.

\begin{tabular}{lll} 
& HVPE & OMVPE \\
\hline \hline Pre-rad & $>5 \mu \mathrm{m}$ & $>5 \mu \mathrm{m}$ \\
Post-rad & $1.6 \mu \mathrm{m}$ & $2.3 \mu \mathrm{m}$
\end{tabular}



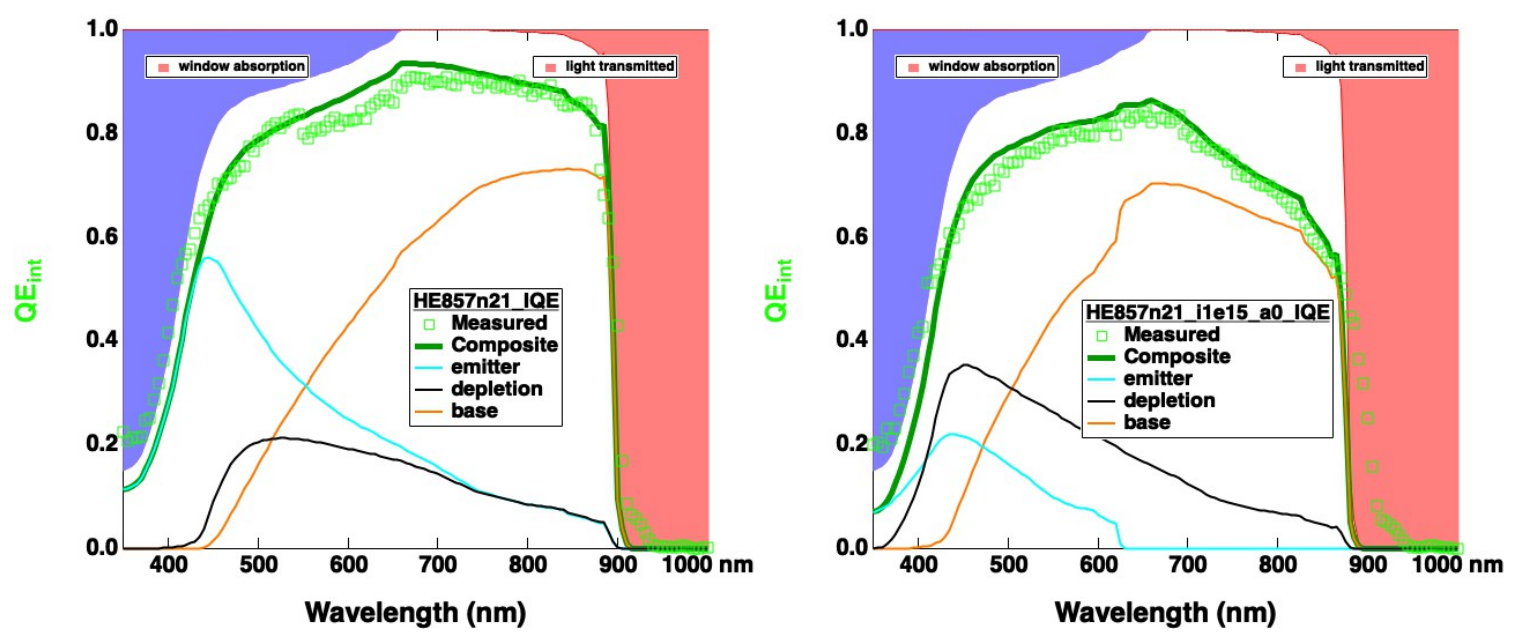

Figure 15. Modeling of the IQE for the HVPE-grown solar cell for both before (left) and after (right) irradiation.

We noted an interesting effect during TRPL measurements. Figure 16 shows carrier lifetimes extracted from TRPL measurements for both HVPE- and OMVPE-grown DHs. These measurements occurred after irradiation. These data show that the lifetime increases as a function of time during the TRPL measurements. The laser light incident on the samples creates a healing effect that reduces some of the radiation degradation. Thinner samples heal more than thicker samples, likely due to the limited penetration depth of the laser light. Previous studies showed healing due to light soaking, but it is unclear if this laser-induced healing is a novel effect. The healing occurred when using a photon fluence of $1 \times 10^{18} \mathrm{~cm}^{-3}$ but did not occur for a fluence of $1 \times 10^{16} \mathrm{~cm}^{-3}$. We estimate that the power of the higher fluence corresponds to a 30x concentration level, albeit at a single wavelength. We did not test the long-term stability of the healing effect and can only say that it was stable over the several minutes required to do the measurements. Both the long-term stability and the underlying physical mechanism warrant additional investigation. Figure 16 again shows that regardless of growth method, at $t=0$ essentially all the samples have the same minority-carrier lifetime, similar to Figure 11, and that at the end of the experiment all of the samples again have roughly the same lifetime. It is likely that the DH structures heal much more than the solar cells due to the much higher illumination intensity during these laser-based measurements.
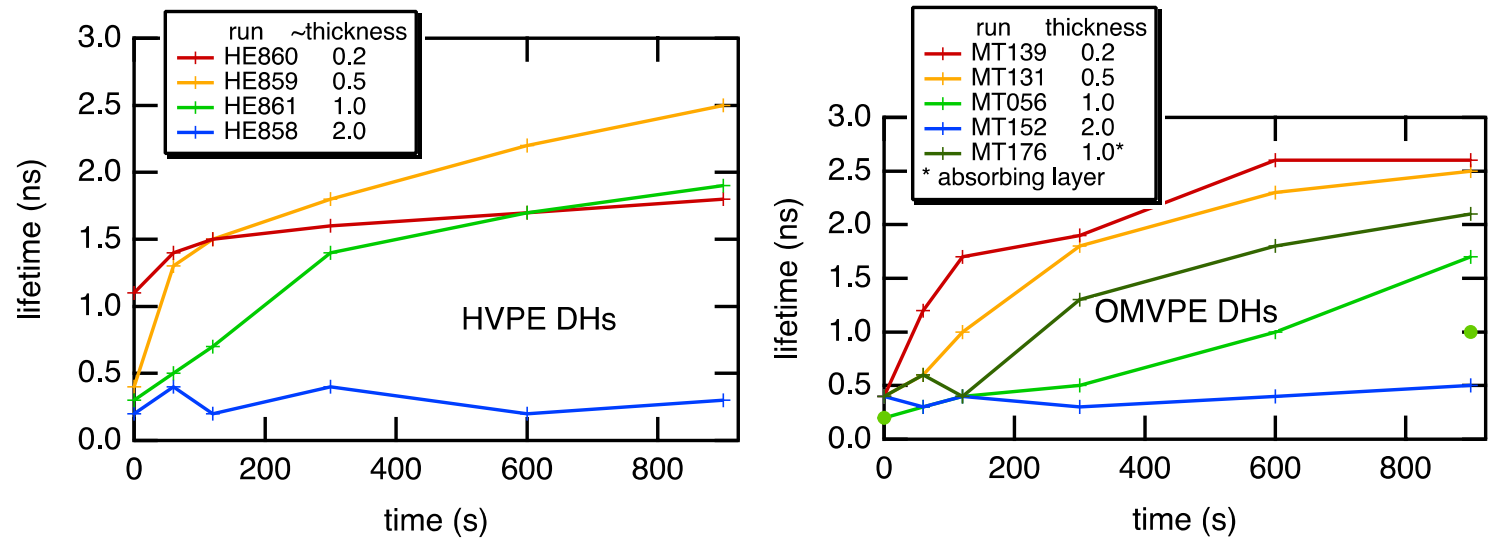

Figure 16. Minority-carrier lifetimes calculated from time-resolved photoluminescence measurements of irradiated DH structures as a function of laser illumination time. 


\section{Conclusions}

In this project we developed front-junction GaAs solar cell structures using HVPE and preliminary graded doping profiles in solar cells grown by both HVPE and OMVPE. These were necessary steps toward hardening the cells to radiation effects. The graded doping in HVPE was complicated by the very long supply lines for the diethylzinc dopant source. We expect that moving the sources closer or other engineering-level changes will alleviate this issue in the future.

We irradiated both solar cells and double heterostructures grown by HVPE and OMVPE using 1 $\mathrm{MeV}$ electrons. Solar cells receiving a fluence of $1 \times 10^{15} \mathrm{~cm}^{-2}$ electrons all had approximately the same $V_{O C}$ regardless of the growth method used. The major difference between the irradiated solar cells was a larger decrease in the $J_{S C}$ of the HVPE-grown devices. We speculated that this could be due to a higher doping level than optimal for this structure.

The purpose of this study was to determine if materials and devices grown using HVPE showed materially different behavior upon irradiation. The work here is preliminary and falls far short of the standards for space qualification. However, there is no indication in the collected data that suggests that HVPE-grown devices will degrade any differently than those currently produced for space applications. 


\section{References}

[1] M. Green, E. Dunlop, J. Hohl-Ebinger, M. Yoshita, N. Kopidakis, and X. Hao, "Solar cell efficiency tables (version 57)," Progress in Photovoltaics: Research and Applications, vol. 29, no. 1, pp. 3-15, 2021, doi: https://doi.org/10.1002/pip.3371.

[2] T. J. Silverman, M. G. Deceglie, B. Marion, S. Cowley, B. Kayes, and S. Kurtz, "Outdoor performance of a thin-film gallium-arsenide photovoltaic module," presented at the Photovoltaic Specialists Conference (PVSC), 2013 IEEE 39th, 16-21 June 2013, 2013.

[3] K. Schulte et al., "Computational fluid dynamics-aided analysis of a hydride vapor phase epitaxy reactor," Journal of Crystal Growth, vol. 434, pp. 138-147, 2016.

[4] J. Simon, K. L. Schulte, K. Horowitz, T. Remo, D. L. Young, and A. J. Ptak, "Enabling a renaissance in III-V-based optoelectronics with low-cost dynamic hydride vapor phase epitaxy," Submitted, 2018.

[5] J. Simon, K. L. Schulte, K. A. W. Horowitz, T. Remo, D. L. Young, and A. J. Ptak, "IIIV-Based Optoelectronics with Low-Cost Dynamic Hydride Vapor Phase Epitaxy," Crystals, vol. 9, no. 1, p. 3, 2018. [Online]. Available: http://www.mdpi.com/2073-4352/9/1/3.

[6] K. L. Schulte, A. Braun, J. Simon, and A. J. Ptak, "High growth rate hydride vapor phase epitaxy at low temperature through use of uncracked hydrides," Applied Physics Letters, vol. 112, no. 4, p. 042101, 2018, doi: 10.1063/1.5013136.

[7] J. F. Geisz, M. A. Steiner, I. García, R. M. France, D. J. Friedman, and S. R. Kurtz, "Implications of Redesigned, High-Radiative-Efficiency GaInP Junctions on III-V Multijunction Concentrator Solar Cells," IEEE Journal of Photovoltaics, vol. 5, no. 1, pp. 418-424, 2015, doi: 10.1109/JPHOTOV.2014.2361014.

[8] Y. Sun, A. Perna, and P. Bermel, "Comparing Front- and Rear-Junction GaInP Photovoltaic Devices Through Detailed Numerical and Analytical Modeling," IEEE Journal of Photovoltaics, vol. 9, no. 2, pp. 437-445, 2019, doi: 10.1109/JPHOTOV.2019.2892530.

[9] S. Kamath, R. C. Knechtli, R. Loo, and B. E. Anspaugh, "Fabrication of high efficiency and radiation resistant GaAs solar cells," presented at the NASA. Lewis Res. Center Solar Cell High Efficiency and Radiation Damage, 1979, 1979, 1979. 


\section{Appendix A}

Table II. Sample descriptions and measurement conditions for all irradiated samples.

\begin{tabular}{|c|c|c|c|}
\hline HVPE Samples & Structure & Size $(\mathrm{mm} \times \mathrm{mm})$ & Fluence $\left(\mathrm{cm}^{-2}\right)$ \\
\hline HE858A & $\mathrm{DH}$ & $10 \times 10$ & $1.00 \mathrm{E}+14$ \\
\hline HE859A & $\mathrm{DH}$ & $10 \times 10$ & $1.00 E+14$ \\
\hline HE860A & $\mathrm{DH}$ & $10 \times 10$ & $1.00 \mathrm{E}+14$ \\
\hline HE861A & $\mathrm{DH}$ & $10 \times 10$ & $1.00 \mathrm{E}+14$ \\
\hline HE858B & $\mathrm{DH}$ & $10 \times 10$ & $5.00 \mathrm{E}+14$ \\
\hline HE859B & $\mathrm{DH}$ & $10 \times 10$ & $5.00 E+14$ \\
\hline HE860B & $\mathrm{DH}$ & $10 \times 10$ & $5.00 E+14$ \\
\hline HE861B & $\mathrm{DH}$ & $10 \times 10$ & $5.00 \mathrm{E}+14$ \\
\hline HE858C & $\mathrm{DH}$ & $10 \times 10$ & $1.00 E+15$ \\
\hline HE859C & $\mathrm{DH}$ & $10 \times 10$ & $1.00 E+15$ \\
\hline HE860C & $\mathrm{DH}$ & $10 \times 10$ & $1.00 \mathrm{E}+15$ \\
\hline HE861C & $\mathrm{DH}$ & $10 \times 10$ & $1.00 \mathrm{E}+15$ \\
\hline HE858D & $\mathrm{DH}$ & $10 \times 10$ & $3.00 \mathrm{E}+15$ \\
\hline HE859D & $\mathrm{DH}$ & $10 \times 10$ & $3.00 E+15$ \\
\hline HE860D & $\mathrm{DH}$ & $10 \times 10$ & $3.00 \mathrm{E}+15$ \\
\hline HE861D & $\mathrm{DH}$ & $10 \times 10$ & $3.00 E+15$ \\
\hline HE857 & FJ Cell & $25 \times 25$ & $1.00 \mathrm{E}+15$ \\
\hline OMVPE samples & Structure & Size $(\mathrm{mm} \times \mathrm{mm})$ & Fluence \\
\hline MS845A & FJ Cell & $15 \times 20$ & $1.00 E+15$ \\
\hline MT130A & FJ Cell & $15 \times 20$ & $1.00 \mathrm{E}+15$ \\
\hline MT302A & FJ Cell & $15 \times 20$ & $1.00 \mathrm{E}+15$ \\
\hline MT131C1 & $\mathrm{DH}$ & $4 \times 8$ & $1.00 \mathrm{E}+14$ \\
\hline MT131C2 & $\mathrm{DH}$ & $6 \times 10$ & $5.00 E+14$ \\
\hline MT131C3 & $\mathrm{DH}$ & $6 \times 10$ & $1.00 \mathrm{E}+15$ \\
\hline MT131C4 & $\mathrm{DH}$ & $4 \times 10$ & $3.00 E+15$ \\
\hline
\end{tabular}




\begin{tabular}{|c|c|c|c|}
\hline MT139C1 & $\mathrm{DH}$ & $4 \times 8$ & $1.00 E+14$ \\
\hline MT139C2 & $\mathrm{DH}$ & $6 \times 10$ & $5.00 \mathrm{E}+14$ \\
\hline MT139C3 & $\mathrm{DH}$ & $6 \times 10$ & $1.00 \mathrm{E}+15$ \\
\hline MT139C4 & $\mathrm{DH}$ & $4 \times 10$ & $3.00 E+15$ \\
\hline MT027C1 & $\mathrm{DH}$ & $4 \times 4$ & $1.00 E+15$ \\
\hline MT027C2 & $\mathrm{DH}$ & $5 \times 10$ & $1.00 E+15$ \\
\hline MT027C3 & $\mathrm{DH}$ & $5 \times 10$ & $1.00 \mathrm{E}+15$ \\
\hline MT027C4 & $\mathrm{DH}$ & $5 \times 10$ & $1.00 E+15$ \\
\hline MT056C2 & $\mathrm{DH}$ & $5 \times 10$ & $5.00 \mathrm{E}+14$ \\
\hline MT056C3 & $\mathrm{DH}$ & $5 \times 10$ & $1.00 E+15$ \\
\hline MT176C1 & $\mathrm{DH}$ & $4 \times 8$ & $1.00 E+14$ \\
\hline MT176C2 & $\mathrm{DH}$ & $6 \times 10$ & $5.00 E+14$ \\
\hline MT176C3 & $\mathrm{DH}$ & $6 \times 10$ & $1.00 \mathrm{E}+15$ \\
\hline MT176C4 & $\mathrm{DH}$ & $4 \times 10$ & $3.00 E+15$ \\
\hline MT152C1 & $\mathrm{DH}$ & $5 \times 10$ & $1.00 \mathrm{E}+14$ \\
\hline MT152C2 & $\mathrm{DH}$ & $6 \times 10$ & $5.00 E+14$ \\
\hline MT152C3 & $\mathrm{DH}$ & $6 \times 10$ & $1.00 E+15$ \\
\hline MT152C4 & $\mathrm{DH}$ & $5 \times 10$ & $3.00 E+15$ \\
\hline MT082C1 & $\mathrm{DH}$ & $5 \times 5$ & $1.00 E+14$ \\
\hline MT082C2 & $\mathrm{DH}$ & $6 \times 10$ & $5.00 E+14$ \\
\hline MT082C3 & $\mathrm{DH}$ & $6 \times 10$ & $1.00 E+15$ \\
\hline MT082C4 & $\mathrm{DH}$ & $5 \times 10$ & $3.00 E+15$ \\
\hline MT065C1 & $\mathrm{DH}$ & $4 \times 8$ & $1.00 E+14$ \\
\hline MT065C2 & $\mathrm{DH}$ & $6 \times 10$ & $5.00 \mathrm{E}+14$ \\
\hline МT065C3 & $\mathrm{DH}$ & $6 \times 10$ & $1.00 E+15$ \\
\hline MT065C4 & $\mathrm{DH}$ & $4 \times 10$ & $3.00 E+15$ \\
\hline MT018C1 & $\mathrm{DH}$ & $5 \times 5$ & $1.00 E+14$ \\
\hline MT018C2 & $\mathrm{DH}$ & $6 \times 10$ & $5.00 E+14$ \\
\hline MT018C3 & $\mathrm{DH}$ & $6 \times 10$ & $1.00 \mathrm{E}+15$ \\
\hline
\end{tabular}




\begin{tabular}{|l|l|l|l|}
\hline MT018C4 & DH & $5 \times 5$ & $3.00 \mathrm{E}+15$ \\
\hline MT131A $^{*}$ & Hall & $10 \times 10$ & $1.00 \mathrm{E}+15$ \\
\hline MT139A $^{*}$ & Hall & $10 \times 10$ & $1.00 \mathrm{E}+15$ \\
\hline MT056A $^{*}$ & Hall & $10 \times 10$ & $1.00 \mathrm{E}+15$ \\
\hline MT176A $^{*}$ & Hall & $10 \times 10$ & $1.00 \mathrm{E}+15$ \\
\hline MT152A $^{*}$ & Hall & $10 \times 10$ & $1.00 \mathrm{E}+15$ \\
\hline MT082A $^{*}$ & Hall & $8 \times 8$ & $1.00 \mathrm{E}+15$ \\
\hline MT065A $^{*}$ & Hall & $10 \times 10$ & $1.00 \mathrm{E}+15$ \\
\hline MT131B $^{*}$ & DiffL & $7 \times 7$ & $1.00 \mathrm{E}+15$ \\
\hline MT139B $^{*}$ & DiffL & $7 \times 7$ & $1.00 \mathrm{E}+15$ \\
\hline MT027B $^{*}$ & DiffL & $7 \times 7$ & $1.00 \mathrm{E}+15$ \\
\hline MT176B $^{*}$ & DiffL & $7 \times 7$ & $1.00 \mathrm{E}+15$ \\
\hline MT152B $^{*}$ & DiffL & $7 \times 7$ & $1.00 \mathrm{E}+15$ \\
\hline MT082B $^{*}$ & DiffL & $5 \times 5$ & $1.00 \mathrm{E}+15$ \\
\hline MT065B $^{*}$ & DiffL & $7 \times 7$ & $1.00 \mathrm{E}+15$ \\
\hline MT018B $^{*}$ & DiffL & $7 \times 7$ & $1.00 \mathrm{E}+15$ \\
\hline
\end{tabular}

* Irradiated but not reported here 